
\title{
25 Research Square \\ Lingering Impacts on Sleep Following the Daylight Savings Time Transition
}

\section{Zachary Owen}

Verily Life Sciences

Sohrab Saeb

Verily Life Sciences

Sarah Short

Verily Life Sciences

Nicole Ong

Verily Life Sciences

Giulia Angi

Verily Life Sciences

Atiyeh Ghoreyshi

Verily Life Sciences

Shannon Sullivan ( $\square$ shannonsul@verily.com )

Verily Life Sciences

\section{Research Article}

Keywords: Daylight Saving Time, sleep period, sleep quality, Baseline Health Study, real world evidence

Posted Date: December 23rd, 2021

DOI: https://doi.org/10.21203/rs.3.rs-1193797/v1

License: (c) (1) This work is licensed under a Creative Commons Attribution 4.0 International License.

Read Full License 


\section{Abstract}

Background: The "spring forward" change to Daylight Savings Time (DST) has been epidemiologically linked with numerous health and safety risks in the days following the transition, but direct measures of sleep are infrequently collected in community dwelling individuals.

Methods: The Project Baseline Health Study (PBHS), a prospective, multicenter, longitudinal representative U.S. cohort study begin in 2017 launched a Sleep Mission in March 2021 to characterize sleep using patient-reported and wearable device measures, in free-living circumstances during the DST switch. Estimated sleep period duration, subjective restedness and quality, and watch metrics were compared before and after the DST transition during specified timeframes.

Results: Of the total PBHS population of 2502 participants, 606 participants received an invitation and 419 participants opted in to the Sleep Mission (69.1\%). The transition to DST resulted in both acute and lingering impacts on sleep. Acute effects included a 29.6 minute reduction in sleep period $(p=0.01)$ and lower ratings of how well participants slept, as well as reduced next-day restedness. In the week following the time change, a persistent reduction in restedness scores, and a trend towards a decrease in sleeping heart rate variability were observed.

Conclusion: The Daylight Savings Time transition is associated with an acute reduction in sleep period, and lingering impacts on self-reported restedness, as well as a trend towards reduced heart rate variability into the week following the transition. This work adds to a growing understanding of the persistence of impacts on sleep health metrics due to the DST transition.

\section{Introduction}

The yearly transition to Daylight Savings Time (DST) each spring has been associated with a myriad of negative health and safety impacts, ranging from stroke[1], myocardial infarction[2] [3], and atrial fibrillation-related hospital admissions.[4] The DST transition has also been associated with traffic crashes and a 6\% increase in traffic fatalities in the first few days following the change.[5] [6] Recent data also indicates a substantial increase in human-error related medical mistakes the first week after switching to daylight saving time.[7] The outcomes are hypothesized to occur for a variety of reasons including circadian timing shifts, light exposure, and sleep loss. In contrast, the longer-lasting (i.e., beyond the first week) effects of DST are less well studied. Because DST results in less morning light and more evening light exposure, it has been argued to be less well-aligned with human circadian biology and possibly contribute to social jet lag and a more chronic state of sleep loss. That said, the small literature on outcomes is mixed, and it has also been reported that the long-term effects of DST may be associated with reduced traffic accidents in the late afternoon due to extension of daylight relative to clock time and other factors.[8]

A number of medical and research societies have published statements in support of elimination of twice-yearly clock time shifts, citing disrupted sleep/wake patterns, reduced total sleep time and quality, 
and pursuant negative health effects.[9] [10] Most studies on the negative health and safety events around the DST transition are unable to relate these outcomes to measures of sleep or subjective assessment of restedness, and there is a need to understand the causes of the detrimental effects of the time change, and potential roles of sleep deprivation and circadian disruption.[11] The object of the present investigation is to measure sleep and subjective sleep experience metrics in a real-world population before, during, and after the transition to DST. The primary aim of this study was to understand the immediate and lingering ( 1 week) impacts of the Daylight Savings Time transition on March 14, 2021 on sleep. The secondary aims of the study were to measure impacts of the time change on subjective morning reports of restedness and how well they slept, and heart rate variability.

\section{Methods}

\section{Population}

All subjects for this investigation were recruited from the Project Baseline Health Study (PBHS). Details for the PBHS are reported elsewhere[12]; in short, the parent cohort study was designed to establish a reference health state and to develop a platform that integrates and analyzes personalized, longitudinal multi-dimensional data. Data from this observational study is collected within a traditional clinical context as well as from day-to-day life of people outside of conventional medical research or clinical care settings. The Spring Forward Sleep Mission was approved both by the Scientific Executive Committee supervising the Baseline Health Study as well as the Western Institutional Review Board.

\section{Study Period}

The study period was March 1 - March 31, 2021.

\section{Recruitment}

On March 1, 2021, an invitation to opt-in to the Spring Forward Sleep Mission was issued via email and via a firmware update to a wrist-worn device, Study Watch, already deployed to measure health variables as part of PBHS. If the watch was not charged and/or updated, the invitation may not have been received on this date.

\section{Inclusion and Exclusion Criteria for Analysis}

Because participants could opt-in to participate in the study at any time point after the invitation was issued, including after March 13, 2021, parameters were set to define the study group for analysis. To be included, participants must have: opted in for the Sleep Mission by end of day March 6, 2021. Even if participants opted in by this date, they were excluded if there was less than one episode of sleep data collection from March 6 to 13, 2021 or from March 14 to 21, 2021. The DST transition occurred at 2am local time on March 14, 2021; for purposes of these analyses, we take the convention of labeling this 
'night' as March 13, 2021. We defined 'night' as the longest sleep interval in the noon-to-noon period commencing on that date. See Supplemental Figure A for details regarding the pool of participants who met these criteria for analysis.

\section{Study Watch}

The Study Watch is a wrist-worn device used in Baseline Health Study for the collection and monitoring of physiological activity and environmental data with high sampling frequency, and in-field assessments of patient-reported data. ${ }^{11}$ Encrypted data collected by the device is transmitted securely via study hub to the secure cloud server. Participants were asked to wear their watch to sleep each night during March 2021. In addition, they were asked to push a button on the side of the Study Watch face to indicate when they got into bed to sleep and when they got out of bed after the intended sleep period. The button-push episodes are termed 'tags' for the purposes of these analyses. Upon completion of each morning tag, participants were asked four questions. These questions appeared in sequential order on the face of the Study Watch directly (example, see Figure 1).

The four questions were:

Question 1: How long did it take you to fall asleep last night?

Question 2: How long did it take you to get out of bed after waking?

Question 3: How well did you sleep last night?

Question 4: How rested do you feel right now?

The participant could respond by scrolling through a range of responses. For questions 1 and 2 , involving time, the following responses were possible: Less than 5 minutes, 5-15 minutes, 15 - 30 minutes, 30-45 minutes, 45-60 minutes, 60-90 minutes, 90-120 minutes, > 120 minutes, and don't know. For the latter two questions: a 5-point smiley face Likert scale was used.

\section{Analysis}

Total Sleep Period (TSP) was calculated based on participant tags, defined as the time from sleep tag start to the sleep tag end, minus sleep onset latency and time from awakening to getting out of bed.[13] From the Study Watch, we also computed overnight heart rate variability (HRV). Overnight HRV was measured by computing the root mean square of successive differences (RMSSD) and the standard deviation of NN intervals (SDNN) within 5 minute intervals and averaging all such intervals for each night of sleep that satisfied the following two criteria: First, the participant had to be wearing the watch for at least $95 \%$ of the night; second, there had to exist at least one hour of heart beat data.[14] For reported sleep times, the midpoint of each range was used for analysis with $>120$ minutes taken to be 150 minutes. Responses reporting don't know were dropped (<2\%). In addition, several subjective sleep related measures were estimated using Study Watch tags. 'Sleeping well' was defined as a participant's 
response to "How well did you sleep last night?" in the top two smileys. 'Sleeping poorly' was defined as a response to this question in the bottom two smileys, which are frowning in various degrees. Well-rested was defined as a participant's response to "How rested do you feel right now?" in the top two smileys. Unrested was defined to be when a participant's response to "How rested do you feel right now?" was in the bottom two smileys.

"Acute" effects of the DST transition were calculated by comparing these metrics for the night starting on Saturday, March 13, 2021, to those of the same participant for the prior Saturday, on March 6, 2021. "Lingering" effects of the DST transition were calculated by comparing these metrics on weekday nights of the week following the DST transition to those of the week prior to the DST transition.

All analyses compare the within-participant means of each metric between the two time frames using paired two-sided t-tests against the null hypothesis of identical means between the time frames. In particular, in the lingering analysis, binary values such as restedness are averaged within participants for all available tags in the week before and the week after the time change. Statistics are reported on the difference of these averages. These averages can be thought of as the daily likelihood of a participant's tag falling into the category under consideration, e.g. reporting restedness.

\section{Results}

By the predetermined final date for Sleep Mission opt-in, March 6, 2021, 606 individuals responded to the invitation and 419 opted in (69.1\% opt-in rate). Of these, 233 participants were randomized to receive an intervention for a separate effort not reported here. The remaining 186 participants were considered to be observational. Of these, 45 were excluded due to having no Study Watch sleep tags collected between March 6 and 13, and 5 additional participants were excluded due to having no such data between March 14 and 21. Table 1 provides demographic and limited medical history information for all 136 participants whose data was included in the analysis. Participants were predominantly female (60.3\%) and white (74.3\%), with a mean age of 61.3 years (Standard Deviation, SD, 15.2 years). The characteristics for the entire Baseline Health Study cohort are reported in the table for comparison.

Acute impacts

Among the 59 participants contributing sleep tags for both the night of the DST transition and the prior Saturday night, the transition to DST resulted in a decrease in total sleep period of 29.6 minutes $(p=0.01)$, from 7 hours and 51 minutes on prior Saturday night to 7 hours and 21 minutes on the night of the transition (Figure 2). In terms of subjective restedness, 31 of the 59 participants had unchanged restedness scores from the week prior. There was a $6.8 \%$ absolute increase in participants whose scores fell into the unrested category ( $\mathrm{p}=0.04$ ), from $1.7 \%$ to $8.5 \%$, a 5 -fold increase in feeling unrested. (Figure 3A). There was also a trend towards fewer participants reporting being rested in the morning following the DST transition, from $62.7 \%$ on March 7 to $49.2 \%$ on March 14, representing a $21.5 \%$ relative decrease in feeling rested after sleep $(p=0.10)$. In addition, there was an $11.9 \%$ increase $(p<0.01)$ from $1.7 \%$ to $13.6 \%$ in participants who reported sleeping poorly on the night of DST transition in comparison to the 
previous Saturday night (Figure 3B). No significant changes in overnight heart rate variability were observed for this group in the acute time frame.

\section{Lingering impacts}

Among the 120 participants contributing at least one sleep tag for the weeknights (ie, nights beginning Sunday through Thursday) in the weeks immediately before and after the DST transition, the number of participants reporting at least one night of 'unrested' sleep increased from 24 to 34 individuals. There was a persistent overall 9.2\% $(\mathrm{p}<0.01)$ absolute reduction in the daily likelihood of reporting restedness, from $49.2 \%$ in the week prior to the DST transition to $40.0 \%$ in the week after the DST transition, a $18.7 \%$ relative decrease. In analysis of heart rate variability in the 99 participants who had this data available at the requisite time points, we observed that nocturnal HRV trended towards reduction after the DST transition but these observations did not reach a $p=0.05$ level of statistical significance. A decrease of $1.21 \mathrm{~ms}$ in mean $\operatorname{RMSSD}(\mathrm{n}=99, \mathrm{p}=0.08)$ and a decrease of $1.29 \mathrm{~ms}$ in $\operatorname{SDNN}(\mathrm{n}=99, \mathrm{p}=0.09)$ (Figure 4) was observed. There was no significant lingering reduction of reported TSP after the DST transition compared to before the transition.

\section{Discussion}

This study characterizes real-world impacts on sleep, subjective restedness and sleep quality, and also reports on a wearable measure of heart rate variability, associated with the "spring forward" DST change. This study offers some insight into the details of DST impacts in a diverse cohort of community dwelling individuals. This offers a novel perspective because while the transition to DST has been epidemiologically associated with negative health and safety impacts, understanding mechanisms including actual amount of sleep loss and trajectory of recovery, if it occurs, changes in sleep timing, measures of patient-reported restedness and sleep experience, and length of time over which negative impacts dissipate - remains incomplete.

As expected, the night of the DST transition was associated with a shorter sleep period compared to the prior week; on the other hand, there was inadequate evidence to suggest that the average participant "lost" an entire hour of sleep. We observed an average reduction in total sleep period of 29.6 minutes. This effect persisted over the following week. The finding of sleep reduction is consistent with other reports in the literature; Lahti et al. found a sleep time reduction of 60.14 minutes in 10 healthy adults as well as sleep efficiency reduction of $10 \%$, whereas assessment of how individuals use their time yields an estimated loss of 15 to 20 minutes of sleep.[15] [16]

Self-reported unrestedness and report of sleeping poorly were increased by the DST transition acutely, and unrestedness persists into the following week. Among those responding to these two questions in the weekdays after the DST transition, a 9.2\% $(p<0.01)$ drop in likelihood to report restedness persisted. These morning reports related to reduced adequacy of sleep and restedness add to the evolving picture of directly measured, self-reported and biophysical impacts of this time shift, and are a novel and convenient way to capture real-time, real-world subjective feedback on sleep. By the second week after 
the DST transition, the study did not uncover ongoing differences in the duration of the reported sleep period compared to the week before the transition. This could be due to differences in the way 'adequate sleep' is captured - and demonstrates a possible disconnect between sleep duration and/or timing, and how refreshed one feels from sleep, when confronted with a circadian challenge.

The question 'how well did you sleep' as a proxy for sleep quality has been well-reported, based on the validated Karolinska sleep diary.[17] [18] It is thought that this question is responsive on a night-to-night basis, as in prior studies, responses after a single night could be correlated to polysomnography findings. [19] This is the first study of which we are aware to pose these questions directly after rising, on a wrist worn device. It is of interest to identify whether this method of obtaining subjective data from participants has greater utility than previous pencil-and-paper methods in real world situations, since participants are queried at a particular point after rising to respond, rather than waiting until later in the morning or day, which may reduce recall bias. This is outside the scope of the present study but merits further investigation.

The trends observed in wearable measures of heart rate - lower HRV during the sleep period - suggests a possible picture of more fragmented, less restful sleep. In a separate analysis of Study Watch wearers during this time frame, we found a reduction in steps taken[20], but there are other considerations here as well - notably that the timing of the light-dark cycle is acutely altered at the DST transition. One argument in favor of DST is that it allows people to get more exercise or engage in more outdoor activity because it 'stays light later', so an interesting area of further research is longer term more complete assessments of activity before and after both the DST and Standard Time transitions. Reduced HRV may be associated with reductions in sleep quality and sleep characterized by arousals, which are associated with increased sympathetic activation. However, HRV is also reduced in slow wave sleep, which may have been increased due to a relative sleep deprivation induced by DST-related sleep loss. Furthermore, REM sleep, which is characterized by increased HRV, may have been reduced by waking at an earlier time in individuals' circadian time following the 'spring forward' time change.

The primary strength of this study is that it combines wearable data and participant self-report on commonly collected sleep diary parameters, as well as real-time, morning assessments of sleep and restedness, to better characterize the possible burden of the DST transition on sleep in community dwelling adults, who were already enrolled in the Project Baseline Health Study. BHS has a communitydwelling cohort which participates in a variety of study-related activities, and the study features a variety of engagement mechanisms, including return of results efforts.[21] Even in this context, the opt-in rate of $69.1 \%$ is very high compared to traditional uptake of studies offered in remote circumstances, for which participation may range between $11 \%$ and $47.4 \%$ in disease specific registry studies between one day and three months long.[22] [23] That said, not all participants who opted in contributed enough data to meet minimum thresholds for analysis, and this may well have affected power to detect changes related to sleep. 
There are a number of limitations inherent in a study of this nature; primary among them are biases related to participation, since those opting in to participate in the study may be fundamentally more interested in or focused upon sleep. Recruitment from the Baseline Health Study, limited participants primarily to geographical areas in North Carolina and California, which may impact light-dark exposures as well as outdoor activity and step count analysis. Such factors may reduce generalizability of the study data. We also note that the participants in the Sleep Mission tended to be middle aged or older adults, and this group may not had the same demands of worklife or family life that younger individuals may have experienced, and this may limit generalizability. Additionally, even among participants meeting the inclusion criteria, not all participants tagged sleep and wore their Study Watch on all nights over the month-long study. While we report the absolute change in number of participants reporting poor restedness and poor sleep before and after the DST transition, we also adjusted for biases in sampling frequency by calculating an average response for each individual participant, for each question, over each period, which we compared before and after DST. It has also been shown that sleep measured using different methodologies yields different measurements; in particular, the agreement between actigraphic measures of sleep and self reported measures of sleep has been estimated between $78-81 \%$, though self reporting in this study was done as close to real-time as possible, and was not retrospective. [24] [25] Additionally, in addition to the primary objective, this investigation explored a number of potential ways of measuring impacts of the DST transition, and was not powered to fully examine each one. Such reported trends require additional study to understand the nature of the impact on DST.

\section{Conclusions}

This study reports on real-world impacts on estimated sleep, subjective restedness and sleep quality, and watch-measured metrics such as heart rate variability, associated with the "spring forward" DST change. Reductions in sleep period were noted on the night of the DST transition. The DST transition also resulted in negative impacts on participants' qualitative sleep experience.

\section{Abbreviations}

BHS Baseline Health Study

DST Daylight Savings Time

HRV Heart Rate Variability

PBHS Project Baseline Health Study

RMSSD Root Mean Square of Successive Differences

SDNN Standard Deviation of N-N Intervals

TSP Total Sleep Period 


\section{References}

[1] Sipilä JO, Ruuskanen JO, Rautava P, Kytö V. Changes in ischemic stroke occurrence following daylight saving time transitions. Sleep Med. 2016 Nov-Dec;27-28:20-24. doi: 10.1016/j.sleep.2016.10.009. Epub 2016 Nov 2. PMID: 27938913.

[2] Manfredini R, Fabbian F, De Giorgi A, et al.. Daylight saving time and myocardial infarction: should we be worried? A review of the evidence. Eur Rev Med Pharmacol Sci. 2018;22(3):750-755.

[3] Janszky I, Ljung R. Shifts to and from daylight saving time and incidence of myocardial infarction. N Engl J Med. 2008;359(18):1966-1968.

[4] Chudow JJ, Dreyfus I, Zaremski L, et al.. Changes in atrial fibrillation admissions following daylight saving time transitions. Sleep Med. 2020;69:155-158.

[5] Ferrazzi E, Romualdi C, Ocello $M$, et al.. Changes in accident \& emergency visits and return visits in relation to the enforcement of daylight saving time and photoperiod. J Biol Rhythms. 2018;33(5):555564

[6] Fritz J, VoPham T, Wright KP, Vetter C. A chronobiological evaluation of the acute effects of daylight saving time on traffic accident risk. Curr Biol. 2020;30(4):729-735.e2.

[7] B Kolla, B J Coombes, T I Morgenthaler, M P Mansukhani, 0173 Spring Forward, Fall Back: Increased Patient Safety-Related Adverse Events Following the Spring Time Change, Sleep, Volume 43, Issue Supplement_1, April 2020, Page A69, https://doi.org/10.1093/sleep/zsaa056.171.

[8] Rachel N. Carey and Kiran M. Sarma, "Impact of Daylight Saving Time on Road Traffic Collision Risk: A Systematic Review," BMJ Open, vol. 7, issue 6 (July 2017), p. e014319

[9] European Biological Rhythms Society; European Sleep Research Society; Society for Research on Biological Rhythms. To the EU Commission on DST. https://esrs.eu/wpcontent/uploads/2019/03/To_the_EU_Commission_on_DST.pdf

[10] Rishi MA, Ahmed O, Barrantes Perez JH, Berneking M, Dombrowsky J, Flynn-Evans EE, Santiago V, Sullivan SS, Upender R, Yuen K, Abbasi-Feinberg F, Aurora RN, Carden KA, Kirsch DB, Kristo DA, Malhotra RK, Martin JL, Olson EJ, Ramar K, Rosen CL, Rowley JA, Shelgikar AV, Gurubhagavatula I. Daylight saving time: an American Academy of Sleep Medicine position statement. J Clin Sleep Med. 2020 Oct 15;16(10):1781-1784.

[11] Malow BA, Veatch OJ, Bagai K. Are Daylight Saving Time Changes Bad for the Brain? JAMA Neurol. 2020 Jan 1;77(1):9-10. doi: 10.1001/jamaneurol.2019.3780. PMID: 31682684.

[12] Arges K, Assimes T, Bajaj V, Balu S, Bashir MR, Beskow L, Blanco R, Califf R, Campbell P, Carin L, Christian V, Cousins S, Das M, Dockery M, Douglas PS, Dunham A, Eckstrand J, Fleischmann D, Ford E, 
Fraulo E, French J, Gambhir SS, Ginsburg GS, Green RC, Haddad F, Hernandez A, Hernandez J, Huang ES, Jaffe G, King D, Koweek LH, Langlotz C, Liao YJ, Mahaffey KW, Marcom K, Marks WJ Jr, Maron D, McCabe R, McCall S, McCue R, Mega J, Miller D, Muhlbaier LH, Munshi R, Newby LK, Pak-Harvey E, Patrick-Lake B, Pencina M, Peterson ED, Rodriguez F, Shore S, Shah S, Shipes S, Sledge G, Spielman S, Spitler R, Schaack T, Swamy G, Willemink MJ, Wong CA. The Project Baseline Health Study: a step towards a broader mission to map human health. NPJ Digit Med. 2020 Jun 5;3:84. doi: 10.1038/s41746020-0290-y. PMID: 32550652; PMCID: PMC7275087.

[13] Aili K, Åström-Paulsson S, Stoetzer U, Svartengren M, Hillert L. Reliability of Actigraphy and Subjective Sleep Measurements in Adults: The Design of Sleep Assessments. J Clin Sleep Med. 2017 Jan 15;13(1):39-47. doi: 10.5664/jcsm.6384. PMID: 27707448; PMCID: PMC5181612.

[14] Shaffer F, Ginsberg JP. An Overview of Heart Rate Variability Metrics and Norms. Front Public Health. 2017;5:258. Published 2017 Sep 28. doi:10.3389/fpubh.2017.00258

[15] Lahti TA, Leppämäki S, Lönnqvist J, Partonen T. Transition to daylight saving time reduces sleep duration plus sleep efficiency of the deprived sleep. Neurosci Lett. 2006 Oct 9;406(3):174-7. doi:

10.1016/j.neulet.2006.07.024. Epub 2006 Aug 22.

[16] Sexton AL, Beatty TKM. Behavioral responses to daylight savings time. J Econ Behav Organ. 2014; 107:290-307.

[17] Akerstedt T, Hume K, Minors D, Waterhouse JThe subjective meaning of good sleep, an intraindividual approach using the Karolinska Sleep Diary. Percept Mot Skills; 1994;791 Pt 1:287-296.

[18] Akerstedt T, Hume K, Minors D, Waterhouse JThe meaning of good sleep: a longitudinal study of polysomnography and subjective sleep quality. J Sleep Res; 1994;33:152-158.

[19] Keklund G, Akerstedt T. Objective components of individual differences in subjective sleep quality. J Sleep Res. 1997 Dec;6(4):217-20. doi: 10.1111/j.1365-2869.1997.00217.x.

[20] Owen Z, Sullivan S, Short S, et al. Real-Time Qualitative and Quantitative Assessment of Sleep during the 2021 "Spring-Forward" to Daylight Savings Time in a Diverse Community Cohort. In: SLEEP 2021, June 12-16, 2021, virtual annual meeting of the Associated Professional Sleep Societies.

[21] Sayeed S, Califf R, Green R, Wong C, Mahaffey K, Gambhir SS, et al. (2021) Return of individual research results: What do participants prefer and expect? PLoS ONE 16(7): e0254153. https://doi.org/10.1371/journal.pone.0254153

[22] Dinur T, Istaiti M, Frydman D, Becker-Cohen M, Szer J, Zimran A, Revel-Vilk S. Patient reported outcome measures in a large cohort of patients with type 1 Gaucher disease. Orphanet J Rare Dis. 2020 Oct 13;15(1):284. doi: 10.1186/s13023-020-01544-z. PMID: 33050940; PMCID: PMC7556970. 
[23] Crouthamel M, Quattrocchi E, Watts S, Wang S, Berry P, Garcia-Gancedo L, Hamy V, Williams RE. Using a ResearchKit Smartphone App to Collect Rheumatoid Arthritis Symptoms From Real-World Participants: Feasibility Study. JMIR Mhealth Uhealth. 2018 Sep 13;6(9):e177.

[24] Girschik J, Fritschi L, Heyworth J, Waters F. Validation of self-reported sleep against actigraphy. J Epidemiol. 2012;22(5):462-468. doi:10.2188/jea.je20120012

[25] Matthews KA, Patel SR, Pantesco EJ, et al. Similarities and differences in estimates of sleep duration by polysomnography, actigraphy, diary, and self-reported habitual sleep in a community sample. Sleep Health. 2018;4(1):96-103. doi:10.1016/j.sleh.2017.10.011

\section{Tables}

Table 1: Study population characteristics, participants who opted in and contributed data for the Sleep Mission 


\begin{tabular}{|c|c|c|}
\hline & $\begin{array}{l}\text { Opt-in to Sleep Mission, } \\
\text { observational group }\end{array}$ & $\begin{array}{l}\text { Baseline Health } \\
\text { Study Cohort }\end{array}$ \\
\hline Number of participants & 136 & 2502 \\
\hline Age, mean (SD) in years & $61.3(15.2)$ & $52.7(17.1)$ \\
\hline Female, N (\%) & $82(60.3 \%)$ & $1375(55.0 \%)$ \\
\hline Enrolled in California, N (\%) & $85(62.5 \%)$ & $1500(60.0 \%)$ \\
\hline \multicolumn{3}{|l|}{ Race/ Ethnicity n(\%) } \\
\hline White & $101(74.3 \%)$ & $1582(63.2 \%)$ \\
\hline Black & $14(10.3 \%)$ & $400(16.0 \%)$ \\
\hline Asian & $11(8.1 \%)$ & $260(10.4 \%)$ \\
\hline Native Hawaiian and/or & $3(2.2 \%)$ & $27(1.1 \%)$ \\
\hline \multicolumn{3}{|l|}{ Pacific Islander } \\
\hline American Indian or & $1(0.7 \%)$ & $31(1.2 \%)$ \\
\hline \multicolumn{3}{|l|}{ Alaska Native } \\
\hline Other race & $6(4.4 \%)$ & $202(8.1 \%)$ \\
\hline Hispanic ethnicity & $7(5.1 \%)$ & $291(11.6 \%)$ \\
\hline \multicolumn{3}{|l|}{ Education n(\%) } \\
\hline High school or less & $6(4.4 \%)$ & $181(7.2 \%)$ \\
\hline Some college & $33(24.3 \%)$ & $475(19.0 \%)$ \\
\hline College & $43(31.6 \%)$ & $676(27.0 \%)$ \\
\hline Graduate degree or higher & $47(34.6 \%)$ & $700(28 \%)$ \\
\hline \multicolumn{3}{|l|}{ Income, n(\%) } \\
\hline$<\$ 25,000$ & $7(5.1 \%)$ & $206(8.2 \%)$ \\
\hline$\$ 25,000-49,999$ & $20(14.7 \%)$ & $264(10.6 \%)$ \\
\hline$\$ 50,000-99,99$ & $32(23.5 \%)$ & $514(20.5 \%)$ \\
\hline$\$ 100,000-149,999$ & $24(17.6 \%)$ & $333(13.3 \%)$ \\
\hline$\$ 150,000-199,999$ & $12(8.8 \%)$ & $201(8.0 \%)$ \\
\hline$>=\$ 200,000$ & $24(17.6 \%)$ & $375(15.0 \%)$ \\
\hline \multicolumn{3}{|l|}{ Marital Status, n(\%) } \\
\hline Married & 73 (53.7\%) & 1105 (44.2\%) \\
\hline
\end{tabular}




\begin{tabular}{|c|c|c|}
\hline Divorced & $14(10.3 \%)$ & $197(7.9 \%)$ \\
\hline Formerly in long term & $4(2.9 \%)$ & $102(4.1 \%)$ \\
\hline \multicolumn{3}{|l|}{ Relationship } \\
\hline Living together & $9(6.6 \%)$ & $213(8.5 \%)$ \\
\hline Never in long term & $14(10.3 \%)$ & $253(10.1 \%)$ \\
\hline \multicolumn{3}{|l|}{ Relationship } \\
\hline Separated & $3(2.2 \%)$ & $52(2.1 \%)$ \\
\hline Widowed & $11(8.1 \%)$ & $79(3.2 \%)$ \\
\hline \multicolumn{3}{|l|}{ Other } \\
\hline Mean PHQ-9 score & 3.1 & 3.7 \\
\hline $\begin{array}{l}\text { Activity; Mean daily steps in first } 30 \\
\text { days, median (IQR) }\end{array}$ & 7802 (4922) & $8423(4829)$ \\
\hline $\begin{array}{l}\text { Self-reported Diagnosis of Sleep Apnea, } \\
n(\%)\end{array}$ & $23(16.9 \%)$ & $171(6.8 \%)$ \\
\hline Insomnia & $77(8.7 \%)$ & \\
\hline \multicolumn{3}{|l|}{ Top 3 Medical Conditions, n(\%) } \\
\hline Hypertension & $48(35.3 \%)$ & $122(4.9 \%)$ \\
\hline Osteoarthritis & $39(28.7 \%)$ & $101(4.0 \%)$ \\
\hline Cataract & 37 (27.2\%) & 97 (3.9\%) \\
\hline
\end{tabular}

\section{Figures}




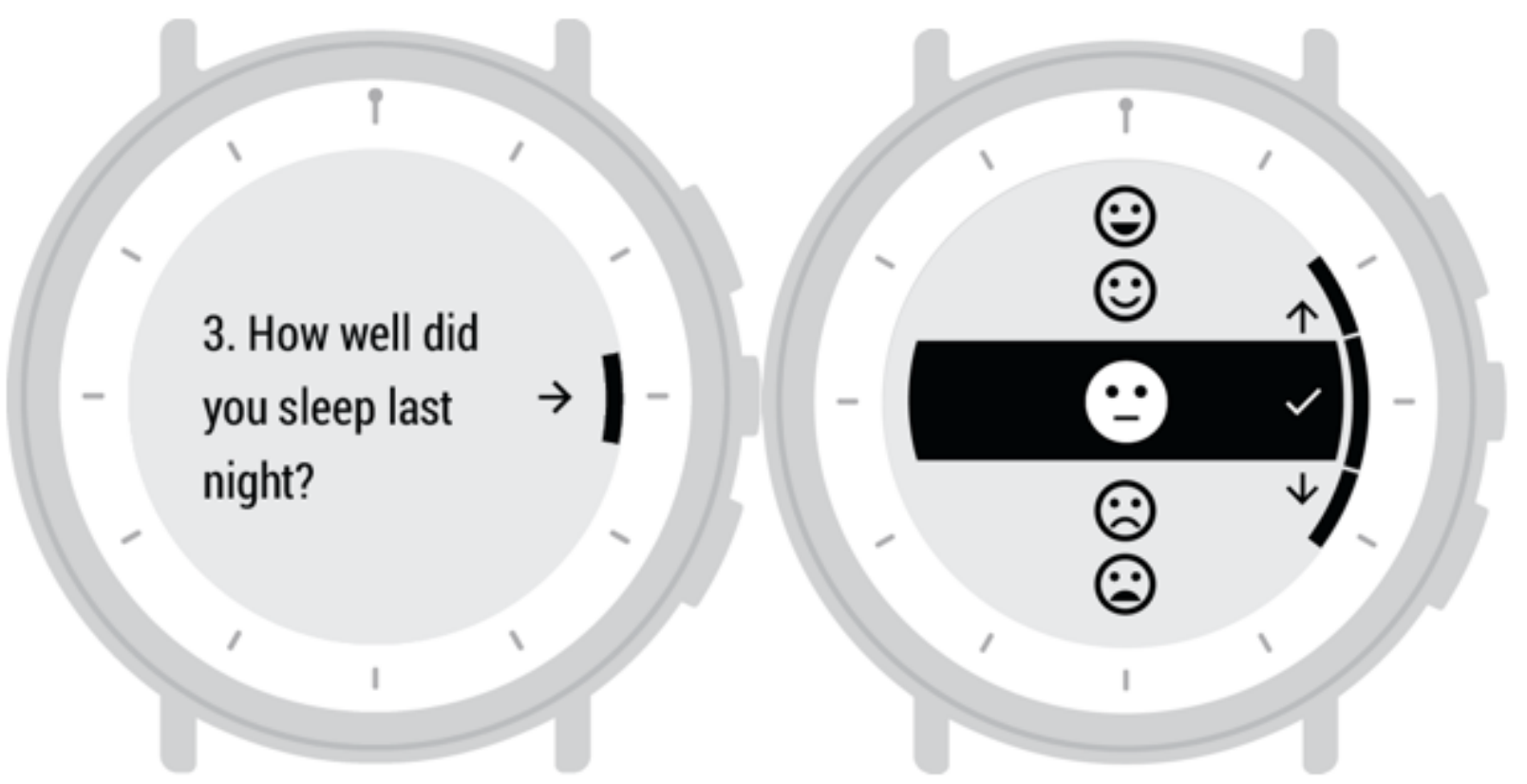

Figure 1

Example of Study Watch Morning Question

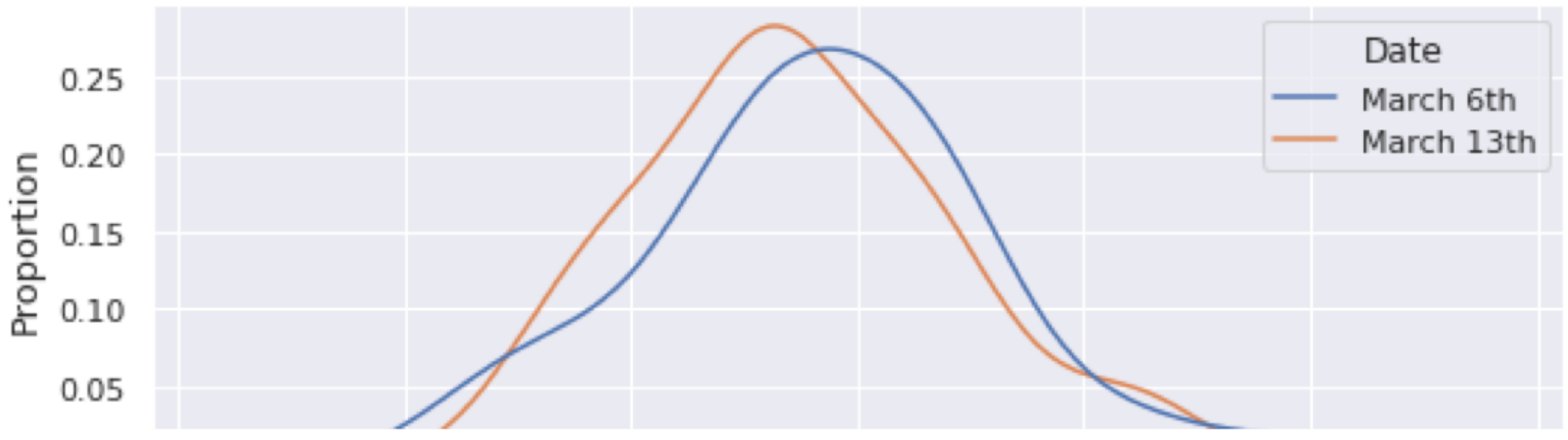

Figure 2

Acute change in Total Sleep Period after the Daylight Savings Time Transition of the group, $n=59$ 
3A.

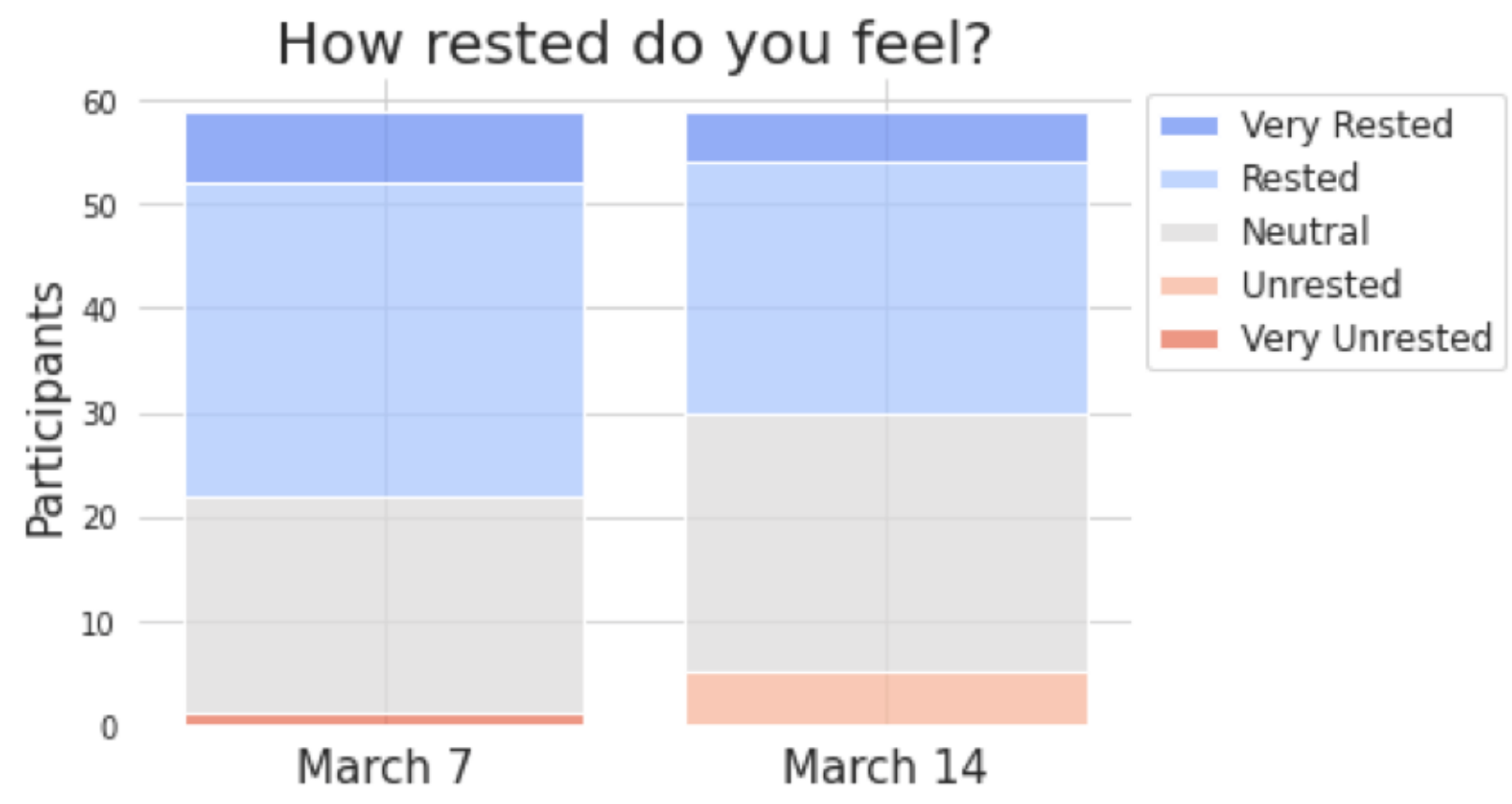

3B.

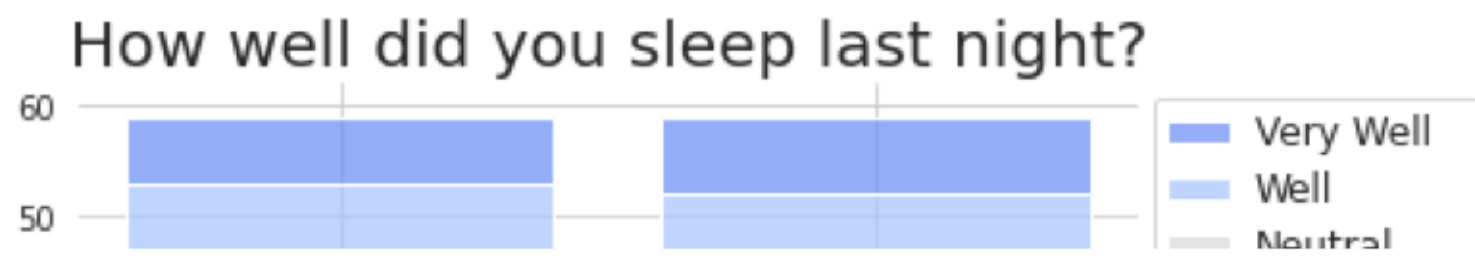

\section{Figure 3}

3A and B: Acute Impacts on Subjective Sleep: Comparing the Saturday nights before and at the Daylight Savings Time transition 


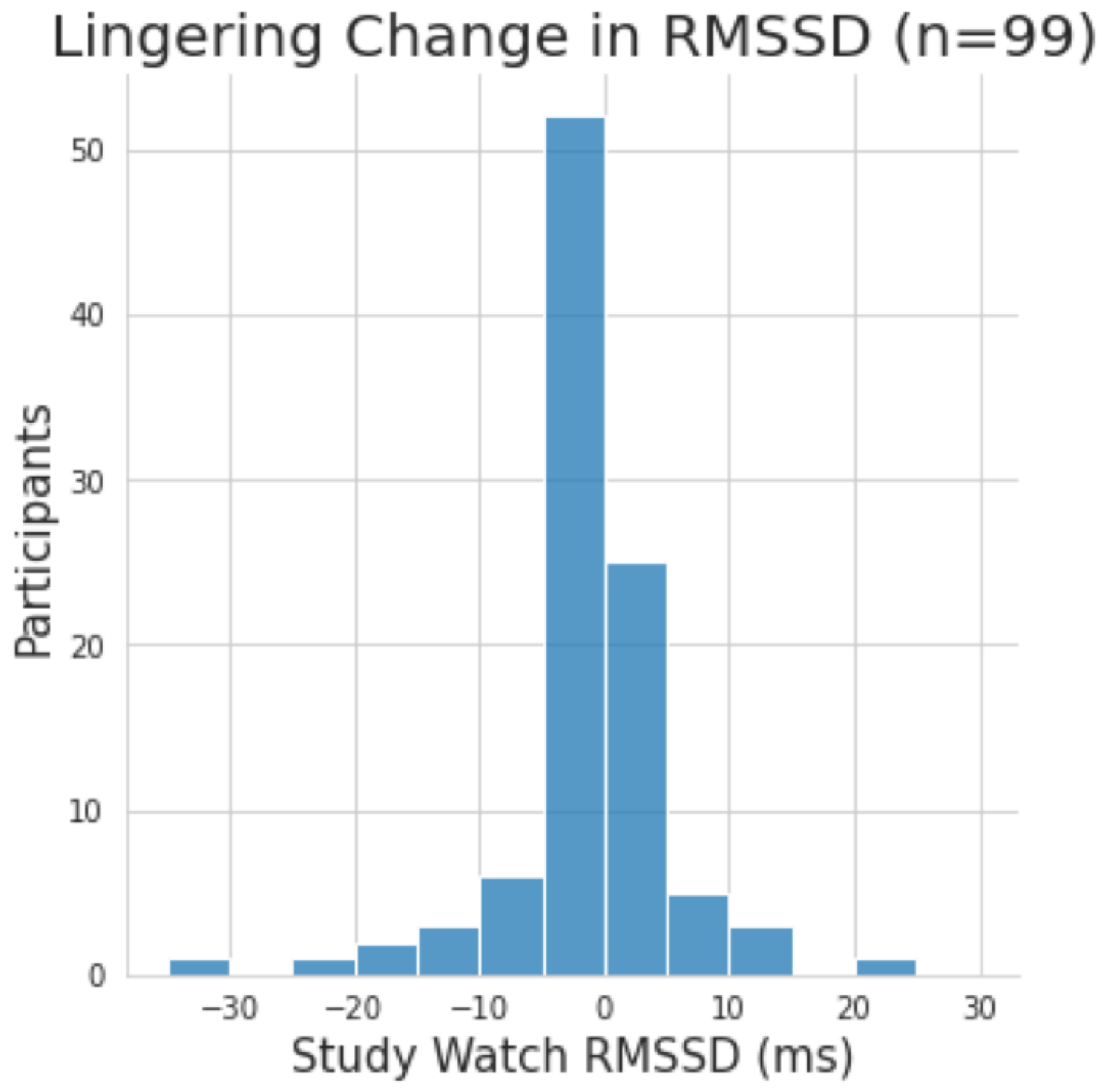

Figure 4

Lingering changes in HRV after the DST transition

\section{Supplementary Files}

This is a list of supplementary files associated with this preprint. Click to download. 
- SupplementFigureA.docx

Page 17/17 